\title{
APEGO MÃE - FILHO: ESTUDO COMPARATIVO ENTRE MÃES DE PARTO NORMAL E CESÁREA
}

\author{
Semíramis Melani Melo Rocha* \\ Érica Simpionato** \\ Débora Falleiros de Mello***
}

\section{Resumo}

Estudo da observação de comportamento através do registro cursivo contínuoespecífico. O objetivo é comparar o comportamento de mães e recém-nascidos de parto normal com o de parto cesárea, nas primeiras 24 horas de vida, em alojamento conjunto neonatal. Observamos 14 binômios mãe-filho, sete de parto normal e sete de cesárea. As observações permitiram conclusões úteis para o cuidado de enfermagem. A voz da mãe e a forma de acariciar o recém-nascido podem ser indicadores da disposição da mãe para cuidar do bebê. As mães de parto cesárea necessitam de mais atenção para iniciarem a amamentação. Ambos apresentam melhor desempenho no cuidado do recém-nascido com o decorrer do período pós-parto. Mães inexperientes ou fragilizadas necessitam de mais atenção. O ambiente pode influir no estabelecimento de vínculos bem sucedidos.

Descritores: enfermagem pediátrica; enfermagem neonatal; vínculos emocionais

\begin{abstract}
The authors chose behavior observation through continuous and specific cursive recording. The purpose was to compare the behavior of mothers and natural-birth newborns with that of caesarian section newborns in their first 24 hours of life in rooming-in. Fourteen mother-child pairs, seven natural births and seven caesarian sections were observed. The observation led to useful conclusions related to nursing care. The mothers' voice and the way they fondle newborns can be indicators of their willingness to take care of the baby. Mothers who have caesarian sections need more attention to begin breastfeeding. In both groups, mothers improved better performance in caring for their newborns over the postpartum period. Inexperienced or fragile mothers need more postpartum attention. The environment can influence the establishment of successful ties.

Descriptors: pediatric nursing; neonatal nursing; mother-object attachment

Title: Mother-newborn attachment: a comparative study among mothers who had natural births and caesarian sections
\end{abstract}

\section{Resumen}

Hemos optado por la observación de comportamiento mediante el registro cursivo continuo-específico. El objetivo es comparar el comportamiento de la madre y el recién nacido de parto normal con la madre y recién nacidos de cesárea durante las primeras 24 horas de vida, en un alojamiento compartido neonatal. Se observaron 14 binomios madrehijo; siete de parto normal y siete de cesárea. Las conclusiones, todas útiles, para el cuidado de enfermería. La voz de la madre y la forma de acariciar al recién nacido pueden ser indicadores de la disposición de la madre para cuidar al bebé. Las madres de parto cesárea necesitan más atención para empezar a amamantar. Las madres de ambos binomios presentan mejor desempeño en el cuidado del recién nacido en el decurso del postparto. Madres sin experiencia o debilitadas emocionalmente necesitan más atención. El ambiente puede influenciar para establecer vínculos bien sucedidos.

Descriptores: enfermería pediátrica; enfermería neonatal; vínculos emocionales Título: Apego madre-hijo: estudio comparativo entre madres de parto normal y cesárea

\section{Introdução}

Inúmeros estudos vêm sendo feitos para responder às perguntas sobre o que favorece, perturba ou deflagra o apego entre pais e bebês, através de observações clínicas, observações naturalistas das funções de pais, entrevistas, observações estruturadas e estudos controlados. Os estudos estendem-se por períodos que antecedem a gravidez, durante a gravidez, parto, nascimento e após nascimento ${ }^{(1-5)}$. Os controles necessários no estudo do apego mãe - filho, possíveis na espécie animal, nem sempre o são no gênero humano. Todos os estudos devem ser considerados dentro de seu contexto. As influências culturais, os valores e as expectativas tanto da mãe como do observador, bem como as estruturas e as políticas de assistência podem alterar ou limitar os resultados.

Uma das perguntas que tem sido feita, com respostas controversas, é se existe um período sensitivo em seres humanos ou não. Estes estudos procuram respostas para perguntas como: o contato íntimo da mãe com o bebê nos primeiros minutos, horas, dias de vida da criança altera a qualidade do apego mãe-filho ao longo do tempo? O ambiente hospitalar, o retardamento do contato íntimo dos pais com o bebê, em conseqüência de partos complicados, más condições de vitalidade da criança têm influência nos sentimentos dos pais pelo bebê? O período sensitivo parece ser um espaço de tempo imediatamente após o nascimento, durante o qual os eventos que ocorrem têm o potencial para influenciar o desenvolvimento do apego. Entretanto, é importante reconhecer que esse desenvolvimento é influenciado por muitos eventos, alguns dos quais ocorrem antes da concepção. Um estudo com base em várias investigações dão apoio ao princípio de um período específico nos seres humanos, logo após o nascimento. Parece que muitos processos são ativados para lançar a mãe para seu bebê, durante os primeiros dias de vida (6). Manter a mãe e o bebê juntos logo após o nascimento parece iniciar e estimular a operação de mecanismos sensoriais, hormonais, fisiológicos, imunológicos e comportamentais conhecidos, que provavelmente vinculam os pais ao bebê. Uma seqüência de interações entre a mãe e o bebê, durante este período, ligando-os um ao outro e assegurando o desenvolvimento posterior do apego reforçam a hipótese deste período sensitivo ${ }^{(6)}$. A exploração deste importante período, após o nascimento, poderá revelar novos conhecimentos que apenas começamos a compreender.

Atualmente, é no hospital que se desenrolam os procedimentos relativos à formação do apego (nascimento) e desapego (morte). As experiências que cercam estes dois eventos na vida de um indivíduo estão sendo despojadas das tradições e dos sistemas familiares de apoio.

Os cuidados a serem prestados à mãe e ao recémnascido nas maternidades, nos alojamentos conjuntos e berçários nas primeiras horas e dias pós-parto, pela enfermagem, envolvem o conhecimento sobre este período chamado sensitivo.

As reações dos bebês recém-nascidos em um ambiente hospitalar são conhecidos e conclui-se ser importante que a equipe de saúde materno-infantil conheça e reforce o relacionamento adequado da mãe com seu filho, propiciando

\footnotetext{
* Professora Titular do Departamento de Enfermagem Materno Infantil e Saúde Pública da EERP/USP.

** Aluna do curso de graduação em Enfermagem da EERP/USP.

*** Professora Doutora do Departamento de Enfermagem Materno Infantil e Saúde Pública da EERP/USP.

E-mail do autor: smmrocha@eerp.usp.br
} 
um desenvolvimento sadio para a criança. O alojamento conjunto, embora tenha sido uma modificação favorável relevante, em relação aos berçários tradicionais, que separavam fisicamente a mãe do recém-nascido, por si só não garante mudanças de atitude ${ }^{(7)}$. São necessárias pesquisas de campo sistemáticas para que a enfermagem, juntamente com demais membros de equipe de saúde possam atuar de forma eficiente.

\section{Objetivo}

Comparar o comportamento de mães e bebês recémnascidos de parto normal com o comportamento de mães e bebês recém-nascidos de parto cesárea, nas primeiras 24 horas de vida, em um alojamento conjunto neonatal.

\section{Metodologia}

Este estudo de natureza qualitativa, constitui-se na observação de comportamentos através do método narrativo com registro cursivo contínuo e específico.

\subsection{Definição de termos}

O apego é definido como um relacionamento ímpar entre duas pessoas, específico e duradouro ao longo do tempo ${ }^{(6)}$. Operacionalmente, são usados como indicadores do apego comportamentos tais como: acariciar, beijar, aconchegar, prolongadas trocas de olhar que servem tanto para manter contato como para mostrar afeição por uma determinada pessoa. Por consenso geral, apego é um laço dos pais com o bebê e vínculo refere-se ao laço na direção oposta, do bebê para os pais. Entretanto, na literatura encontramos apego com o mesmo significado para relações nas duas direções.

\subsection{Estratégia}

A observação do comportamento é utilizada pela psicologia, sendo amplamente empregada em pesquisas desenvolvidas sob o enfoque de diferentes abordagens teóricas, tais como etologia, análise aplicada do comportamento e ecologia. A importância atribuída às estratégias observacionais vincula-se, sobretudo, às suas possibilidades de fornecer respostas a questões previamente formuladas, avaliar o repertório comportamental dos sujeitos e os resultados de intervenções. Pode-se obter um quadro mais fiel do comportamento estudado do que aquele fornecido por outros métodos de coleta de dados, como por exemplo, relatos e entrevistas ${ }^{(8)}$.

As técnicas de observação do comportamento se desenvolveram concomitantemente com o estudo do comportamento de crianças, a partir do século XIX, e ao longo dos anos, muitas estratégias foram desenvolvidas e aperfeiçoadas, procurando atender às várias necessidades dos estudos.

As estratégias observacionais podem ser classificadas em três métodos principais: narrativo, amostragem e classificação. Selecionamos para esta pesquisa o método narrativo, que descreve os eventos comportamentais tal como eles ocorrem, preservando as suas seqüências temporais e propiciando informações numerosas e detalhadas sobre os comportamentos em estudo. Dessa forma, o pesquisador primeiro registra os eventos observados e só após seleciona, classifica e analisa os comportamentos. O método narrativo abarca as descrições diárias, os registros de incidentes críticos e os registros cursivos ${ }^{(8)}$

Os registros cursivos são realizados dentro de um período de tempo ininterrupto e consistem em registrar detalhadamente o que ocorre numa determinada situação, de acordo com a seqüência temporal dos fatos, de forma que se possam visualizar os eventos observados como de fato ocorreram.
Por serem contínuos no tempo, tais registros são também denominados de registros contínuos. Para o propósito deste estudo, o observador fez o registro da atuação materna relativa a voz, forma de acariciar, amamentação, maneira como olha para o recém-nascido, troca de fraldas, maneira como fala de seu filho para outras puérperas e quando o recém-nascido chora. Foram observados também movimentos do recémnascido e o ambiente. Essa seleção prévia caracteriza a observação como registro cursivo contínuo específico .

Os registros realizados por meio desta técnica são relativos à localização, posição e postura do sujeito; a eventos comportamentais, tais como respostas motoras, expressões faciais e respostas vocais, e eventos ambientais, tais como mudanças que ocorrem nos ambientes físico e social durante o período de observação. Dessa forma, pretende-se um levantamento inicial do repertório comportamental de mães e seus bebês recém-nascidos e uma descrição das circunstâncias ambientais nas quais esses comportamentos ocorreram.

As categorias descritivas do comportamento correspondem às fases ativamente determinadas de mudanças encontradas em uma forma de intercâmbio organismoambiente (operação de comportamento), movimento, postura ou aparência previamente exibidos. Em nosso caso, comportamentos relacionados à interação entre a mãe e o recém-nascido.

A denominação das categorias de comportamento é uma questão de convenção. O nome adotado foi o que mais pronta e convenientemente evocou a definição da categoria em causa, em termos de serem observáveis. Assim, a voz foi categorizada em não verbaliza, verbaliza muito, verbaliza pouco, com alteração da entonação, sem alteração da entonação e verbaliza com voz infantil. Mas não se deve esquecer que o nome apenas rotula uma descrição ou enunciado, para economia de expressão: desta forma deve-se ter o cuidado de aplicá-lo apenas a fenômenos que comportam a descrição que ele designa. Foi utilizado um roteiro de observação, para anotação das observações.

\subsection{Local}

Para o desenvolvimento deste trabalho foram estudadas puérperas e recém-nascidos internados na Maternidade do Complexo Aeroporto - Fundação e Maternidade Sinhá Junqueira - MATER Ribeirão Preto - SP, na unidade de alojamento conjunto, no período das primeiras 24 horas após o nascimento do recém - nascido que apresentavam quadro clínico estável.

\subsection{Aspectos Éticos}

Antes de iniciarmos a pesquisa, o projeto foi enviado ao Comitê de Ética em Pesquisa do Hospital das Clínicas da Faculdade de Medicina de Ribeirão Preto da Universidade de São Paulo e ao Diretor Clínico da Maternidade do Complexo Aeroporto - Fundação e Maternidade Sinhá Junqueira - MATER, sendo aprovado por ambos.

As mães observadas receberam informação sobre a pesquisa e consentiram na participação através de autorização por escrito.

\subsection{Procedimentos}

Inicialmente foi explicado a cada puérpera o desenho do estudo que seria realizado, solicitando seu consentimento por escrito, conforme as normas do Comitê de Ética em Pesquisa. Para garantir o anonimato, cada mãe e seu respectivo recémnascido recebeu um número na apresentação dos resultados.

A observadora permaneceu com as puérperas e com seu recém-nascido por dois períodos, com duração de 3 horas cada, em plantões distintos, nas primeiras 24 horas que 
sucederam ao parto. A primeira observação foi realizada entre o nascimento e até 12 horas de vida do recém-nascido, a segunda observação entre 12 e 24 horas de vida. Os resultados são utilizados numa reflexão sobre cuidados às mães e bebês nas primeiras horas após o parto e não devem ser tomados como comportamentos padronizáveis.

\subsection{Descrição do ambiente}

A Maternidade do Complexo Aeroporto-Fundação e Maternidade Sinhá Junqueira - MATER se compõe por centro obstétrico, sala pré-parto, consultórios, recepção, berçário para recém-nascidos que apresentem algum risco e um alojamento conjunto. Esta unidade de alojamento conjunto contém 44 leitos e 44 berços, distribuídos em 14 quartos, sendo oito quartos com quatro leitos e quatro berços e seis quartos com dois leitos e dois berços. Os quartos se dispõem pareados lado a lado. A MATER possui duas entradas, sendo uma somente para funcionários e estagiários e outra para pacientes e visitas. A Maternidade atende a gestante, a puérpera e o recém-nascido. $\mathrm{Na}$ unidade de alojamento conjunto são atendidos as puérperas e seus recém-nascidos. O atendimento é feito por médicos, enfermeiros, auxiliares e técnicos de enfermagem. Pela manhã, os procedimentos realizados são: exames físicos nas mães; banho, curativo umbilical e exame físico nos recém-nascidos. Neste momento, as mães são incentivadas a realizarem esses procedimentos juntamente com os profissionais. As mães, em geral ficam atentas e algumas participam, enquanto outras preferem somente observar o que está sendo realizado. No início da tarde, os profissionais realizam exame físico nas puérperas e no seu respectivo recém-nascido. No restante da tarde, estes são atendidos conforme as necessidades que se apresentam. Familiares e amigos das puérperas visitam-nas à tarde. A limpeza dos quartos é feita diariamente à tarde. Observa-se que, pela manhã, há maior movimentação nos quartos, com entrada de profissionais e estagiários em maior freqüência. Os cuidados e procedimentos terapêuticos à puérpera e recém-nascido são concentrados no período da manhã. A tarde há pouca movimentação no ambiente, desta maneira, as puérperas tendem a descansar. A maioria das mães se mostrou receptiva aos profissionais, abertas ao aprendizado de técnicas de como cuidar de seu recém-nascido. Em média, as puérperas têm recebido alta hospitalar 24 horas após o parto.

\section{Resultados}

Foram observados 14 binômios mãe-filho, durante as primeiras 24 horas de vida do recém-nascido, sendo sete de parto normal e sete de parto cesárea. O período de observação foi de 11 de maio de 2001 a 23 de janeiro de 2002.

O quadro 1 nos mostra que o perfil das mães observadas é semelhante quanto a escolaridade. Entre as mães de parto normal, uma é considerada adolescente. Houve mais primíparas entre as mães de parto cesárea e quanto ao estado civil, houve mais casadas entre as mães de parto normal.

Entre os sete recém-nascidos de parto normal, dois eram do sexo feminino e cinco do sexo masculino. O peso dos recémnascidos variou entre 2060 e 3390 gramas e a altura variou entre 46 e 50 centímetros. Entre os recém-nascidos de parto cesárea, cinco eram do sexo feminino e dois do sexo masculino. O peso variou entre 2205 a 3965 gramas e a altura variou entre 44 e 50 centímetros.(Quadro 2). O perfil dos recém-nascidos foi semelhante nos dois grupos, em relação a estas variáveis.

Apresentamos a seguir a discussão sobre as categorias de comportamentos observados em recém-nascidos e mães nas primeiras 12 horas após o nascimento e entre 12 e 24 horas após o nascimento dos recém-nascidos de parto normal e cesárea.
Quadro 1 -Identificação das mães segundo a idade, estado civil, número de filhos e escolaridade. Maternidade do Complexo Aeroporto-Fundação e Maternidade Sinhá Junqueira-Mater. Ribeirão Preto-SP, 2001/ 2002.

\begin{tabular}{|c|c|c|c|c|c|}
\hline \multicolumn{2}{|r|}{ Mães } & Idade & $\begin{array}{l}\text { Estado } \\
\text { civil }\end{array}$ & $\begin{array}{l}\mathrm{N}^{0} \text { de } \\
\text { filhos }\end{array}$ & Eescolaridade \\
\hline \multirow{7}{*}{ 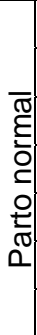 } & 01 & 20 anos & casada & 1 filho & $1^{\circ}$ grau incompleto \\
\hline & 02 & 31 anos & casada & 2 filhos & $1^{\circ}$ grau incompleto \\
\hline & 03 & 31 anos & casada & 2 filhos & $1^{\circ}$ grau incompleto \\
\hline & 04 & 25 anos & casada & 2 filhos & $2^{\circ}$ grau incompleto \\
\hline & 05 & 27 anos & casada & 2 filhos & $1^{\circ}$ grau incompleto \\
\hline & 06 & 16 anos & amasiada & 2 filhos & $1^{\circ}$ grau incompleto \\
\hline & 07 & 26 anos & amasiada & 4 filhos & $1^{\circ}$ grau incompleto \\
\hline \multirow{7}{*}{ 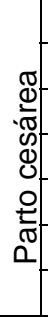 } & 08 & 28 anos & amasiada & 3 filhos & $1^{\circ}$ grau incompleto \\
\hline & 09 & 26 anos & solteira & 1 filho & $1^{\circ}$ grau incompleto \\
\hline & 10 & 25 anos & solteira & 1 filho & $2^{\circ}$ grau completo \\
\hline & 11 & 28 anos & casada & 3 filhos & $1^{\circ}$ grau completo \\
\hline & 12 & 32 anos & casada & 3 filhos & $1^{\circ}$ grau incompleto \\
\hline & 13 & 21 anos & amasiada & 2 filhos & $1^{\circ}$ grau incompleto \\
\hline & 14 & 20 anos & solteira & 1 filho & $1^{\circ}$ grau completo \\
\hline
\end{tabular}

Quadro 2 -Identificação dos recém-nascidos segundo peso, altura, sexo, idade gestacional, tipo de parto. Maternidade do Complexo Aeroporto-Fundação e Maternidade Sinhá Junqueira-Mater. Ribeirão PretoSP, $2001 / 2002$.

\begin{tabular}{|c|c|c|c|c|c|}
\hline \multicolumn{2}{|r|}{ RN } & Peso (g) & Altura (cm) & Sexo & Parto \\
\hline \multirow{7}{*}{ 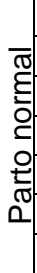 } & 01 & 2695 & 46,0 & Masculino & Normal \\
\hline & 02 & 3390 & 50,0 & Masculino & Normal \\
\hline & 03 & 3340 & 50,0 & Masculino & Normal \\
\hline & 04 & 2060 & 48,0 & Masculino & Normal \\
\hline & 05 & 2930 & 47,5 & Feminino & Normal \\
\hline & 06 & 2855 & 46,5 & Masculino & Normal \\
\hline & 07 & 3140 & 48,5 & Feminino & Normal \\
\hline & & & & & \\
\hline & 08 & 2840 & 49,5 & Feminino & Cesárea \\
\hline$\stackrel{\widetilde{d}}{\mathscr{Q}}$ & 09 & 3385 & 50,0 & Feminino & Cesárea \\
\hline 坣 & 10 & 3830 & 48,5 & Feminino & Cesárea \\
\hline 仓ั & 11 & 3580 & 49,0 & Masculino & Cesárea \\
\hline 원 & 12 & 2205 & 44,0 & Feminino & Cesárea \\
\hline वे & 13 & 2240 & 44,0 & Masculino & Cesárea \\
\hline & 14 & 3965 & 48,5 & Feminino & Cesárea \\
\hline
\end{tabular}

Voz: Comparação entre o primeiro e o segundo período de observação: as mães passam a verbalizar mais no segundo período de observação, quando aparece com mais freqüência a alteração da intonação da voz e a verbalização com voz infantil.

Comparação entre mães de parto normal e parto cesárea: a freqüência de verbalização é maior entre as mães de parto normal. A freqüência de alteração de intonação da voz á maior entre as mães de parto normal, no primeiro período de observação. A verbalização com voz infantil é mais freqüente entre mães de parto cesárea no primeiro período de observação.

Forma de acariciar: Comparação entre o primeiro e o segundo período de observação: entre as formas de acariciar, no primeiro período foram mais freqüentes aproximar o corpo e segurar no colo, tanto em mães de parto normal quanto cirúrgico. No segundo período, entre as mães de parto normal, foram mais freqüentes segurar no colo, acariciar o corpo do recémnascido e abraçar. Entre as mães de parto cesárea, no segundo período de observação foram mais freqüentes, aproximar do corpo, acariciar a face, segurar no colo e abraçar. 
Comparação entre as mães de parto normal e parto cesárea: As formas de acariciar aproximar o corpo e segurar no colo aparecem nos dois grupos com a mesma freqüência . Acariciar a face e abraçar apareceu com mais freqüência entre as mães de parto cesárea. Nos dois grupos acariciar muito o recém-nascido aparece com mais freqüência no segundo período de observação.

Amamentação: Comparação entre o primeiro e o segundo período de observação em partos normais: todas as mães amamentaram nos dois períodos, sendo mais freqüente amamentar sentadas. No primeiro período duas mães amamentaram deitadas e três no segundo período. Acariciar enquanto amamenta, conversar com o recém-nascido e sorrir foi mais freqüente no segundo período de observação. As mães demonstraram mais habilidade para amamentar no segundo período de observação. Ficar com o recém-nascido no colo, após amamentá-lo, apresentou a mesma freqüência nos dois períodos.

Comparação entre o primeiro e segundo período de observação em partos cesárea: uma mãe não amamentou no primeiro período de observação. No primeiro período foi mais freqüente amamentar deitada e, no segundo período, foi mais freqüente amamentar sentada. Acariciar enquanto amamenta, conversar com o recém-nascido, estimular o recém-nascido para mamar, sorrir enquanto amamenta e ficar com o recémnascido no colo após amamentá-lo foram mais freqüentes no segundo período de observação. Amamentar com habilidade foi mais freqüente no segundo período de observação.

Comparação entre as mães de parto normal e parto cesárea: olhar para o recém-nascido enquanto amamenta é o comportamento mais freqüente nos dois períodos de observação, entre os dois grupos de mães. As mães de parto cesárea apresentaram, com maior freqüência o comportamento conversar com o recém-nascido e acariciar o recém-nascido no segundo período de observação. As mães de parto cesárea amamentaram deitadas em maior freqüência do que as mães de parto normal, no primeiro período de observação. Amamentar com habilidade é mais freqüente entre as mães de parto normal no primeiro período de observação. No segundo período de observação é um comportamento apresentado por todas as mães observadas, tanto de parto normal como cesárea. No primeiro período de observação, estimular o recém-nascido para mamar, ficar com o recém-nascido no colo e sorrir enquanto amamenta são mais freqüentes entre as mães de parto normal e no segundo período a freqüência é a mesma entre os dois grupos.

Maneira como olha para o recém-nascido: Olhar fixamente o recém-nascido foi um comportamento apresentado por todas as mães de parto normal e de parto cesárea nos dois períodos. Sorrir enquanto olha é um comportamento bastante freqüente. Olhar face-a-face apresentou baixa freqüência.

Troca de fraldas: Comparação entre o primeiro e segundo período de observação: a troca de fraldas ocorreu com mais freqüência no segundo período de observação tanto entre mães de parto normal quanto em mães de parto cesárea. No segundo período, quando ocorreu, a troca de fraldas foi com habilidade acompanhada de observação do genital.

Comparação entre as mães de parto normal e de parto cesárea: as mães de parto cesárea no segundo período de observação trocaram a fralda em maior freqüência. Conversar com o recém-nascido aparece com mais freqüência entre as mães de parto normal. Entre as mães que trocaram as fraldas do recém-nascido, todas observaram os genitais, com a mesma freqüência, tanto as mães de parto normal quanto as de parto cesárea. Movimentos suaves aparecem com mais freqüência no segundo período de observação, entre as mães de parto cesárea.

Maneira como fala de seu filho para outras puérperas: Comparação entre o primeiro e segundo período de observação: a conversa entre as mães foi mais intensa no segundo período de observação, tanto entre mães de parto normal quanto parto cesárea.

Comparação entre as mães de parto normal e de parto cesárea: no primeiro período de observação as mães de parto normal verbalizaram com mais freqüência. No segundo período, as mães de parto cesárea verbalizaram com maior freqüência.

Atuação materna durante o choro: No primeiro período de observação, duas mães de parto normal não atuaram durante o choro de seu recém-nascido. No segundo período de observação as mães de parto normal atenderam prontamente ao choro do recém-nascido com mais freqüência.

Os comportamentos, pegar no colo, embalar e oferecer o peito, se intensificam no segundo período de observação entre as mães de parto cesárea. O comportamento acalmar o recém-nascido conversando aparece com mais freqüência entre as mães de parto cesárea no segundo período de observação. O choro foi menos freqüente no segundo período de observação tanto para o recém-nascido de parto normal quanto de parto cesárea.

No primeiro período, as mães de parto cesárea atenderam prontamente ao choro, pegaram no colo, embalaram e ofereceram o peito com mais freqüência que as mães de parto normal. O choro foi mais intenso nos recém-nascidos de parto cesárea e todas as mães de parto cesárea atuaram durante o choro no primeiro período. No segundo período, as mães cujos recém-nascidos choraram, todas pegaram no colo. O comportamento embalar e oferecer o peito ocorreu com maior freqüência nas mães de parto cesárea. Acariciar ocorreu igualmente nos dois grupos

Movimentos do recém-nascido: Os recém-nascidos de parto normal apresentaram maior freqüência do movimento mão-boca no primeiro período de observação. O olhar alerta foi observado nos dois períodos entre os recém-nascidos de parto normal e cesárea. Os dois grupos de recém-nascidos procuraram sugar com maior freqüência no segundo período de observação.

Ambiente: No primeiro período de observação o ambiente das mães de parto normal apresentava-se com maior movimentação de pessoas e com mais visitas do que o ambiente das mães de parto cesárea. No segundo período o ambiente apresentou-se com pouca movimentação de pessoas nos dois grupos e com mais visitas no grupo das mães de parto cesárea.

\section{Discussão}

A voz da mãe e a forma de acariciar o recém-nascido devem ser cuidadosamente observados, durante os cuidados de enfermagem, podem ser indicadores da disposição da mãe para cuidar do recém-nascido. Constatamos que sua disposição para manifestar estes comportamentos vai se intensificando com o passar das horas.

Amamentar é um momento crítico nas primeiras 24 horas após o nascimento. Observa-se que as mães de parto cesárea necessitam de mais atenção que as mães de parto normal. Tanto as mães de parto normal quanto cesárea, apresentam melhor desempenho, com o decorrer do período após o parto. Esta variação no desempenho de amamentar, sugere maior atenção da enfermeira nas primeiras 12 horas após o parto.

Olhar para o recém-nascido e falar sobre ele é um indicador do cuidado que a mãe está prestando ao seu recémnascido. Ambos os grupos de mães demonstram intensidade no olhar. A verbalização entre as mães de parto cesárea, vai se intensificando com o passar das horas.

A troca de fraldas e atuação materna durante o choro, são indicadores do desenvolvimento das habilidades maternas para cuidar do bebê. É responsabilidade da enfermeira estar atenta para estes comportamentos, e auxiliar as mães mais 
inexperientes, ou mais fragilizadas após o parto, transmitindoIhes segurança. Logo após o parto, tanto mães de parto normal, como cesárea, são mais inseguras.

Os movimentos do recém-nascido são indicadores de uma interação importante entre mãe e filho. Os comportamentos maternos são estimulados pelos comportamentos do recémnascido.

Enfatizamos a importância de ajudar a mãe a estar atenta ao seu bebê e responder afetivamente as suas demonstrações de estabelecer contato.

O ambiente representa não só o espaço físico, mas o conjunto dos elementos que constituem a cultura e o referencial de atuação. O parto hospitalar, a equipe profissional , as visitas e os procedimentos realizados conformam a rede de interações. Destaca-se que não existem padrões típicos naturais ou ideais de categorias de comportamentos facilitadores ou antagônicos ao estabelecimento de uma relação entre a mãe e o recémnascido ${ }^{(9)}$.

A interação entre mãe e filho é um sistema aberto, capaz de transformação e reorganização dinâmica. As prédisposições em jogo são as garantias de sobrevivência física. São também predisposições para o desenvolvimento de um sistema de adaptação, integração e desenvolvimento do indivíduo na realidade social, meio natural da espécie humana (9).

A antiga imagem de um bebê que não via nem escutava por várias semanas após o nascimento contribuiu para cegar os pais à rica gama de reações infantis que colaboram para fortalecer rapidamente o apego. Hoje, as capacidade sensoriais do recém-nascido são mais conhecidas e os profissionais que dão apoio aos pais podem indicar-lhes toda riqueza do repertório comportamental da criança. O comportamento do recémnascido e as respostas instintivas dos pais confluem, no período pós-natal, para alimentar o crescimento do apego entre as duas partes. Os pais que apreciam e valorizam esta riqueza estão prontos a entrar num diálogo mais rico com seu bebê ${ }^{(10)}$

A escolha da pessoa objeto de apego está muito mais na dependência do grau de responsividade e de iniciativa para a interação do que em satisfação de necessidades primárias da criança. Desta forma, o recém-nascido está mais propenso a estabelecer relação de apego com a pessoa que interage com ele, do que com a pessoa que o alimenta e cuida de sua higiene corporal, sem se preocupar em manter os sinais de reciprocidade na comunicação interativa.

Os estados de consciência do recém-nascido correspondem as ações da mãe, cada vez que uma ação sua evoca uma resposta, a mãe tem sua competência confirmada (10).

\section{Considerações finais}

A comparação de categorias de comportamento observadas de mães e recém-nascidos de parto normal e cesárea, nas primeiras 24 horas de vida do recém-nascido, em um alojamento conjunto neonatal permitiu algumas considerações úteis para o trabalho de enfermagem. Ao cuidar do binômio mãe-filho a enfermeira deve considerar seu papel como facilitadora da relação de apego. Para tanto deve conhecer o referencial teórico e os indicadores desta relação. Desenvolver a observação de comportamento da mãe e do recém-nascido requer treinamento específico.

Assim, sugerimos que a enfermeira desenvolva metodologias de assistência de enfermagem apropriadas para o levantamento de dados (assesment) e diagnóstico de enfermagem para prestar o cuidado em alojamento conjunto neonatal que propiciem uma rede de relações interativas entre a mãe, o bebê e os profissionais. A enfermeira deve atuar, também propiciando a segurança da mãe e do recém-nascido para estabelecer vínculos bem sucedidos com o recémnascido.

Agradecimentos: Trabalho financiado pelo Conselho Nacional de Desenvolvimento Científico - CNPq e Fundação de Amparo a Pesquisa do Estado de São Paulo - FAPESP.

\section{Referências}

1. Muller ME. Prenatal and postnatal attachment: a modest correlation. Journal of Obstetric, Gynecologic and Neonatal Nursing, Philadelphia (PA) 1996 Feb;25(2):161-6.

2. Goulet C, Bell L, St-Cyr Tribble D, Paul D, Lang A. A concept analysis of parent-infant attachment. Journal of Advanced Nursing, Oxford 1998 Nov;28(5):1071-81.

3. Fowles ER. Relationships among prenatal mater not attachment, presence of post natal depressive symptoms and maternal role attainment. Journal of the Society of Pediatric Nurses, Philadelphia (PA) $1996 \mathrm{Jul} / \mathrm{Sept} ; 1(2): 75-82$.

4. Eiden R, Teti DM, Corns KM. Maternal working models of attachment, marital adjustment, and the parent-child relationship. Child Development, Chicago (IL) 1995 Oct;66(5):1504-18.

5. Scochi CGS, Mello DF, Melo LL, Gaiva MAM. Assistência aos pais de recém-nascidos pré-termo em unidades neonatais. Revista Brasileira de Enfermagem, Brasília (DF) 1999 out/dez;52(4):495-503.

6. Klaus MH, Kennell JH. Pais/bebê: a formação do apego. Porto Alegre (RS): Artes Médicas; 1993. 329 p. il.

7. Gasparetto S, Bussab VSR. Padrões e estados comportamentais de recém-nascidos durante o banho em maternidade: possibilidades de regulação e trocas sociais. Revista Brasileira de Crescimento e Desenvolvimento Humano, São Paulo 2000 jan/jun;10(1):39-48.

8.Dessen MAC, Borges LN. Estratégias de observação do comportamento em psicologia do desenvolvimento. In: Romanelli G, Biasoli-Alves ZMM, organizadores. Diálogos metodológicos sobre prática de pesquisa. Ribeirão Preto (SP): Légis Summa; 1998. 178 p. p. 31-50.

9. Branco AU. A relação mãe-criança: considerações sobre a ontogênese da "natureza" social do ser humano. Psicologia: Teoria e Pesquisa, Brasília (DF) 1987 set/dez;3(3):296-300.

10.Brazelton TB, Cramer BG. As primeiras relações. São Paulo (SP): Martins Fontes; 1992. 287 p. il. (Coleção psicologia e pedagogia).

Data de recebimento: 20/02/2003

Data de aprovação: 26/06/2003 